\title{
CARACTERIZAÇÃO DO REGIME PLUVIOMÉTRICO NO ARCO DAS NASCENTES DO RIO PARAGUAI
}

\author{
JULIANO ARAUJO MARTINS ${ }^{1}$, RIVANILDO DALLACORT ${ }^{2}$, MIRIAN HIROKO INOUE ${ }^{2}$, EDINÉIA \\ APARECIDA DOS SANTOS GALVANIN ${ }^{3}$, ELISANDRA BATISTA ZAMBENEDETTI MAGNANI ${ }^{4}$ E \\ KELSIANE CARDOSO OLIVEIRA ${ }^{2}$
}

\author{
${ }^{1}$ Escola Superior de Agricultura Luiz de Queiroz (ESALQ), Departamento de Engenharia de Biossistemas, \\ Piracicaba, SP, Brasil \\ ${ }^{2}$ Universidade do Estado de Mato Grosso (UNEMAT), Departamento de Agronomia, Tangará da Serra, MT, \\ Brasil \\ ${ }^{3}$ Universidade do Estado de Mato Grosso (UNEMAT), Departamento de Matemática, Barra do Bugres, MT, \\ Brasil \\ ${ }^{4}$ Universidade Federal de Mato Grosso (UFMT), Cuiabá, MT, Brasil \\ julianoaraujo@usp.br, rivanildo@pq.cnpq.br
}

Recebido Maio de 2010 - Aceito Junho de 2011

\begin{abstract}
RESUMO
Na região do arco das nascentes do Rio Paraguai, é grande a pressão das atividades antrópicas sobre o meio ambiente, com destaque para a agricultura. Deste modo, estudos que visem distinguir padrões climáticos desta região são imprescindíveis, pois convêm como subsídio a modelos agrícolas que obtiveram uma melhor relação entre produção e dispêndio de energia. Objetivou-se então neste trabalho, analisar a distribuição anual, sazonal e mensal das precipitações, ocorrência de dias secos e chuvosos, bem como, estipular diferentes níveis probabilísticos de precipitação utilizando a função Gama. A média de precipitação da região foi de $1.513,97 \mathrm{~mm}$, sendo que deste total $50,26 \%$ ocorreram no verão e apenas 2,69\% no inverno. Os meses com maiores médias de precipitação foram Novembro, Dezembro, Janeiro, Fevereiro e Março. Em contraponto os meses de Junho, Julho e Agosto apresentaram as menores médias, sendo este comportamento semelhante para toda a região em questão. A precipitação esperada a $75 \%$ de probabilidade, durante o período chuvoso, variou de $229,98 \mathrm{~mm}$, em Janeiro no Município de Tangará da Serra, a 83,85 mm, em Novembro no município de Barra do Bugres. Palavras-chave: Precipitação, distribuição temporal, níveis de probabilidade
\end{abstract}

\begin{abstract}
RAINFALL REGIME CHARACTERIZATION ON THE ARC OF PARAGUAY RIVER HEADWATERS

The arc of Paraguay River headwaters area is subjected to great pressure of human activities on the environment, especially due to agriculture. Thus, studies that aim to analyze the weather patterns in this region are essential, for their importance as subsidy to agricultural models that visualize the best relation between production and energy consumption. The objective of this work was to analyze the yearly, seasonal and monthly rainfall distribution, as well as to provide different levels of precipitation probability, using the Gamma function. The average rainfall at the region was 1,513.97 $\mathrm{mm}$, being that $50.26 \%$ of this occurred on the summer and only $2.69 \%$ on the winter. The months with highest rainfall average were from November to March, and the lowest from the months of June and August, characterizing the whole region. The expected rainfall at $75 \%$ of probability during the rainy season, ranges from $229.98 \mathrm{~mm}$ in January at the municipal district of Tangará da Serra, to $83.85 \mathrm{~mm}$ in November at Barra do Bugres.
\end{abstract}

Keywords: Rainfall, temporal distribution, levels of probability 


\section{INTRODUÇÃO}

A bacia do Alto Paraguai é caracterizada como uma região de alta pressão ecológica, de grande interesse científico em nível nacional e mundial, devido sua localização entre as áreas de transição dos biomas Amazônico, Cerrado e Pantanal. A região possui grandes áreas de exploração agrícola e pecuária, entre as quais podem ser destacadas culturas como soja, milho, cana de açúcar e criação animal, principalmente de bovinos (Collischonn et al., 2003).

De acordo com Cunha e Junk (2004) o uso inadequado do solo e dos recursos hídricos nesta região vem gerando grande quantidade de sedimentos, que ao longo dos anos têm ocasionado assoreamento dos rios e oscilações nos padrões de alagamento na planície pantaneira. Tais sedimentos são carreados em sua maioria pela ocorrência de chuvas intensas, que extrapolam a capacidade de infiltração de água dos solos, formando enxurradas.

Para a agricultura, tanto o excesso como o déficit hídrico podem trazer efeitos negativos a atividade. $O$ primeiro onera o manejo de água e solo, agravando os processos de degradação ambiental (Ranieri et al., 1998), já o segundo compromete todo o balanço energético das plantas, que ao serem submetidas a estresse hídrico reduzem a absorção de nutrientes e fixação de biomassa, promovendo mecanismos de defesas contra o ambiente hostil, ocasionando gastos de energia que poderiam ser despendidos em produção (Fontana, 1992).

A aplicação de estudos agroclimatológicos, nos Programas de Zoneamento Agrícola do Brasil, passou a orientar os produtores quanto aos tipos de cultura e épocas de plantio mais favoráveis a cada região (Assad et al., 2001). O conhecimento prévio de como a precipitação pluviométrica se comportará é apresentado como alicerce ao desenvolvimento destes projetos, por se tratar de um parâmetro base às técnicas de cultivo que visam aperfeiçoar a utilização dos recursos naturais, no intuito de obter a melhor relação entre produção e gasto de energia (Smith, 2000).

Diversos estudos ligados a análise de padrões pluviométricos, vem sendo desenvolvidos no país entre os quais podem ser citados os trabalhos realizados por Mello et al. (2001), Minuzzi et al. (2006), Murta et al. (2005), Silva et al. (2007), Lima et al. (2008), tornando-se ferramentas de suma importância ao planejamento agrícola local.

Keller Filho et al. (2005) objetivaram identificar regiões pluviometricamente homogêneas no Brasil, tendo sido catalogadas 25 macrozonas distintas em toda extensão territorial brasileira. No entanto, para análise pontual do comportamento das chuvas, estas informações podem mascarar as características microzonais existentes em cada região.

Na região da Bacia do Alto Paraguai, a disponibilidade de dados climáticos é escassa, tendo em vista a existência de apenas uma estação para grande extensão de área. Além deste fato, as informações existentes são poucas ou insignificantemente exploradas. Neste contexto, objetivou-se no presente trabalho determinar a variabilidade anual, mensal e decendial das chuvas, quantificar o número de dias secos e chuvosos, além de estimar diferentes níveis probabilísticos de precipitação para períodos mensais na região onde estão localizadas as nascentes do Rio Paraguai e também seus principais afluentes.

\section{DADOS E METODOLOGIA}

Os dados de precipitação utilizados no desenvolvimento do presente trabalho foram disponibilizados pelo Instituto Nacional de Meteorologia (INMET) e Agência Nacional de Águas (ANA), com histórico de dados variando de 34 a 47 anos (Tabela 1), cujas estações estão localizadas conforme a Figura 1.

O clima da região, segundo Köppen é classificado como Aw, ou seja, clima quente e úmido, com estação chuvosa no verão e estiagem no inverno, caracterizando o clima como estacional (Nimer, 1989).

Para a organização dos dados, verificação da consistência, determinação de médias e desvio padrão da precipitação para períodos mensais, sazonais e anuais utilizou-se o software CLIMA desenvolvido pelo Instituto Agronômico do Paraná (IAPAR) (Faria et al., 2003). As médias anuais foram correlacionadas com a altitude local da respectiva estação, de modo a verificar a influência deste fator com a variação espacial dos elementos em estudo.

A análise da ocorrência de dias secos e chuvosos foi realizada com base na metodologia proposta por Sans e Santana (2002), onde estes consideraram como secos, dias em que a precipitação foi igual ou inferior a $5 \mathrm{~mm}$, e chuvosos, quando a precipitação foi igual ou superior a $5,1 \mathrm{~mm}$.

Na determinação de diferentes níveis de probabilidade de precipitação, utilizou-se o modelo probabilístico da distribuição Gama incompleta, descrito por Thom (1958), onde sua função densidade de probabilidade é dada conforme Equação 1.

$$
F(x)=\frac{1}{\beta^{\alpha} \Gamma(\alpha)} \int_{0}^{x} u^{\alpha-1} e^{\frac{u}{\beta}} d u
$$

Em que:

$\alpha$ - parâmetro de forma (adimensional);

$\beta$ - parâmetro de escala $(\mathrm{mm})$;

e - base do logaritmo neperiano;

u- variável aparente utilizada para integração;

$\mathrm{x}$ - total de precipitação $(\mathrm{mm})$; e

$\Gamma(\alpha)$ - símbolo da função gama, definida conforme Equação 2. 
Tabela 1 - Coordenadas geográficas e período de observação das estações meteorológicas em estudo.

\begin{tabular}{lccccc}
\hline \multicolumn{1}{c}{ Estação } & Órgão & Latitude & Longitude & Altitude & Histórico \\
\hline Barra do Bugres & ANA & $15^{\circ} 19^{\prime} \mathrm{S}$ & $57^{\circ} 14^{\prime} \mathrm{W}$ & $147,0 \mathrm{~m}$ & 1972 a 2007 \\
Cáceres & INMET & $16^{\circ} 03^{\prime} \mathrm{S}$ & $57^{\circ} 41^{\prime} \mathrm{W}$ & $118,0 \mathrm{~m}$ & 1961 a 2008 \\
Cuiabá & INMET & $15^{\circ} 33^{\prime} \mathrm{S}$ & $56^{\circ} 07^{\prime} \mathrm{W}$ & $151,3 \mathrm{~m}$ & 1961 a 2007 \\
Diamantino & INMET & $14^{\circ} 24^{\prime} \mathrm{S}$ & $56^{\circ} 27^{\prime} \mathrm{W}$ & $286,3 \mathrm{~m}$ & 1961 a 2008 \\
Jaciara & ANA & $15^{\circ} 59^{\prime} \mathrm{S}$ & $54^{\circ} 58^{\prime} \mathrm{W}$ & $258,7 \mathrm{~m}$ & 1966 a 2008 \\
Nobres & ANA & $14^{\circ} 39^{\prime} \mathrm{S}$ & $56^{\circ} 07^{\prime} \mathrm{W}$ & $365,0 \mathrm{~m}$ & 1973 a 2007 \\
Rondonópolis & ANA & $16^{\circ} 28^{\prime} \mathrm{S}$ & $54^{\circ} 39^{\prime} \mathrm{W}$ & $235,5 \mathrm{~m}$ & 1966 a 2008 \\
Tangará da Serra & ANA & $14^{\circ} 38^{\prime} \mathrm{S}$ & $57^{\circ} 28^{\prime} \mathrm{W}$ & $300,0 \mathrm{~m}$ & 1970 a 2007 \\
\hline
\end{tabular}

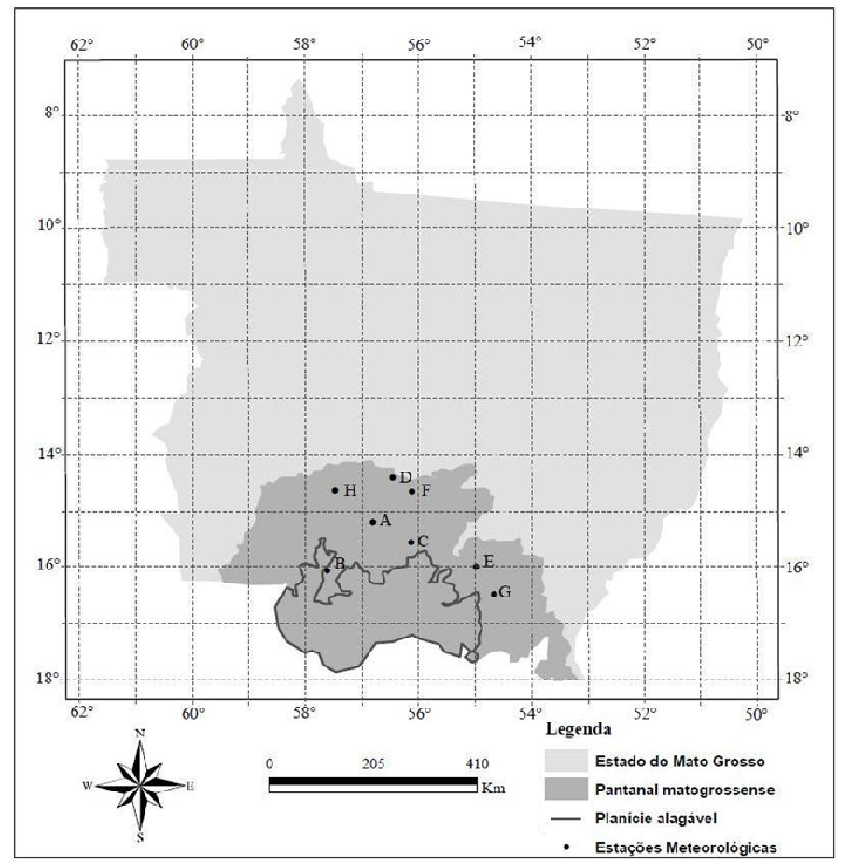

Figura 1 - Localização das estações em estudo: A. Barra do Bugres, B. Cáceres, C. Cuiabá, D. Diamantino, E. Jaciara, F. Nobres, G. Rondonópolis, H. Tangará da Serra.

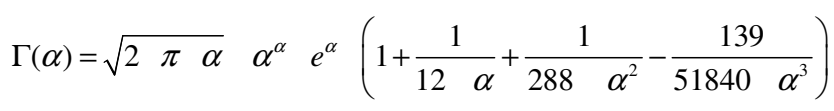

Os parâmetros de forma $(\alpha)$ e escala $(\beta)$ que possibilitam o cálculo da distribuição Gama acumulada para uma dada variável aleatória foram estimados pelo método dos momentos, conforme as Equações 3 e 4 (Assis et al., 1996).

$$
\begin{gathered}
\alpha=\frac{\bar{X}^{2}}{S^{2}} \\
\beta=\frac{S^{2}}{\bar{X}}
\end{gathered}
$$

Para verificar o ajuste dos dados estimados aos observados, utilizou-se o teste de aderência de KolmogorovSmirnov ao nível de 5\% de significância, onde não se encontrou alguma discrepância significativa para períodos mensais. Deste modo, procedeu-se a determinação das precipitações prováveis nos níveis de 10, 25, 50, 75 e 90\% de probabilidade, para subseqüente análise e discussão dos dados.

\section{RESULTADOS E DISCUSSÃO}

A maior média anual de precipitação foi registrada no município de Tangará da Serra, com 1.830,88 mm, em contrapartida o município de Barra do Bugres apresentou a menor média de precipitação, com 1.208,64 mm, sendo a média geral da região igual a 1.513,97 mm (Figura 2). O município de Rondonópolis apresentou o maior desvio padrão (360,49 mm), enquanto que o menor foi observado no município de Cáceres (187,72 mm), estes resultados indicam que o primeiro município possui a maior variação interanual de precipitação, ocorrendo o contrário no segundo.

Observam-se na distribuição sazonal das chuvas (Figura 2), quatro períodos distintos para a região em estudo, sendo um período chuvoso que vai de Novembro a Março, concentrando os maiores índices de precipitação, que em média equivale a $74,34 \%$ das chuvas, seguido de um período de transição entre o período seco e chuvoso (transição 1) com tendência a declínio dos índices de precipitação nos meses de Abril e Maio, onde ocorrem $10,74 \%$ das chuvas; posteriormente nos meses de Junho, Julho e Agosto, a precipitação incidida corresponde a apenas 2,58\%, caracterizando o período seco e por fim nos meses de Setembro e Outubro, ocorrem novamente as primeiras precipitações significativas acumulando valores de $12,34 \%$, sendo estes os meses de transição entre o período seco e chuvoso (transição 2).

A maior contribuição da estação chuvosa ao regime pluviométrico anual verifica-se em Nobres com 76,72\% das chuvas ocorrendo nesta estação, em contraponto a menor contribuição foi registrada em Cuiabá, onde este valor representa 


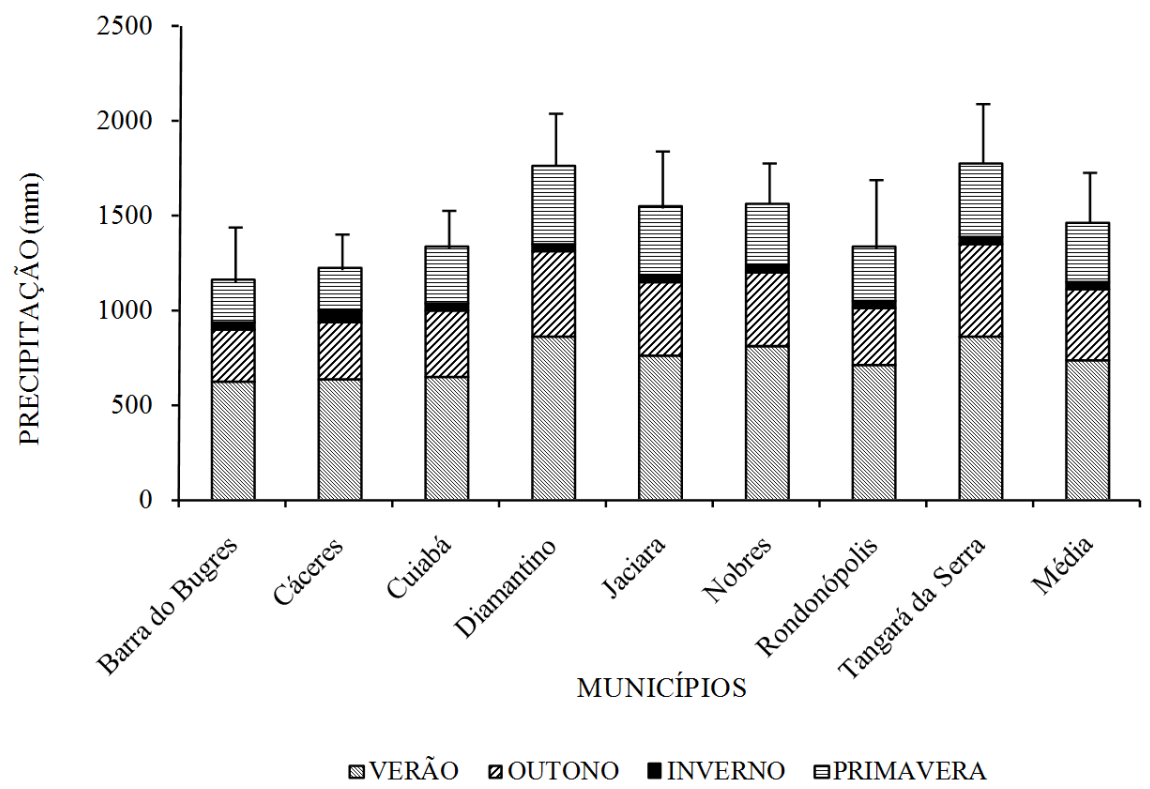

Figura 2 - Média anual e sazonal do regime pluviométrico na região do arco das nascentes do Rio Paraguai.

$72,40 \%$ (Figura 2), indicando grande regularidade no percentual de contribuição da estação chuvosa em toda a região.

$\mathrm{Na}$ estação de transição entre o período chuvoso e o seco (transição 1), os extremos são observados nos municípios de Tangará da Serra e Barra do Bugres, onde as precipitações médias ocorridas no período correspondem a 12,26 e 9,58\%, respectivamente (Figura 2). As chuvas ocorridas no período seco têm insignificante contribuição ao regime pluviométrico, tendo seu limite superior no município de Cáceres, com 4,52\%, e inferior em Nobres, com $1,74 \%$. A média de precipitação na estação de transição do período seco para o chuvoso (transição 2) tem seus limites nos municípios de Jaciara e Cáceres, onde na primeira $23,59 \%$ das precipitações ocorrem neste período, enquanto que na segunda registrou-se apenas 18,53\% (Figura 2).

Observa-se uma correlação positiva equivalente a 0,839 entre a altitude da estação com a média anual de precipitação, indicando que a elevação local tem uma ligação de $83,9 \%$ com as variações espaciais dos níveis médios de precipitação anual (Figura 3). O mesmo comportamento foi observado por Carvalho e Assad (2005) em estudo realizado no Estado de São Paulo.

As médias mensais de precipitação para os municípios em estudo estão ilustradas na Figura 3. Em geral, observa-se que o período onde ocorrem as menores lâminas de precipitação, para todos os municípios, corresponde aos meses de Junho, Julho e Agosto, visto que em nenhuma das estações, as médias superaram a níveis de $25 \mathrm{~mm}$. Segundo Dias et al. (1999), a existência de períodos com baixa precipitação nos meses de inverno, é benéfico ao rendimento industrial da cana-

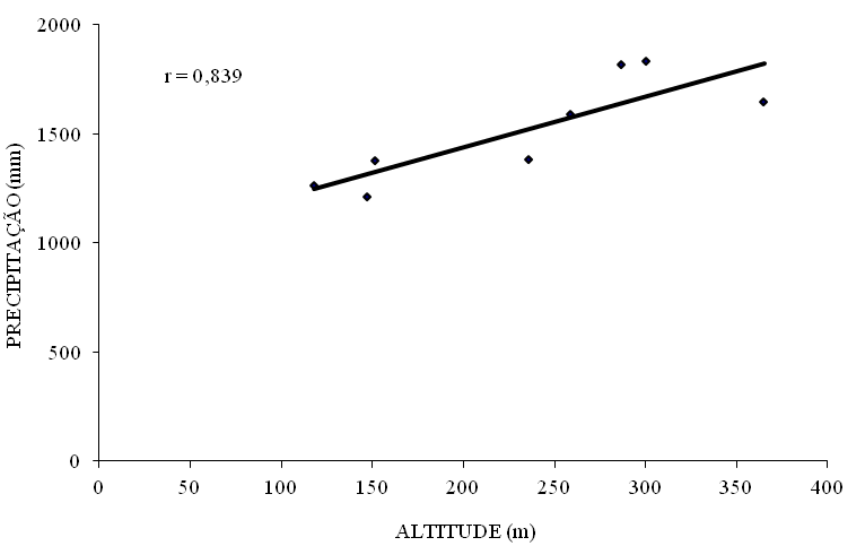

Figura 3 - Correlação entre altitude e precipitação na região do arco das nascentes do Rio Paraguai

de-açúcar. Por outro lado este comportamento inviabiliza o desenvolvimento de outras atividades agrícolas como, por exemplo, a terceira safra de feijão, que nos cerrados só é possível com a utilização de irrigação total (Figuerêdo et al., 2008).

$\mathrm{O}$ período em que ocorrem os maiores índices pluviométricos na região, situa-se entre Novembro e Março, no entanto existem variações significativas entre os níveis médios de ocorrência entre as estações. Os municípios de Diamantino (Figura 4d), Nobres (Figura 4f) e Tangará da Serra (Figura 4h), apresentaram nos meses de Dezembro, Janeiro, Fevereiro e Março, índices pluviométricos mensais acima de $250 \mathrm{~mm}$, já o município de Jaciara (Figura 4e), apenas em Dezembro e Janeiro as médias superaram $250 \mathrm{~mm}$, fato que ocorreu em Rondonópolis (Figura 4g) somente no mês de Janeiro. 
A
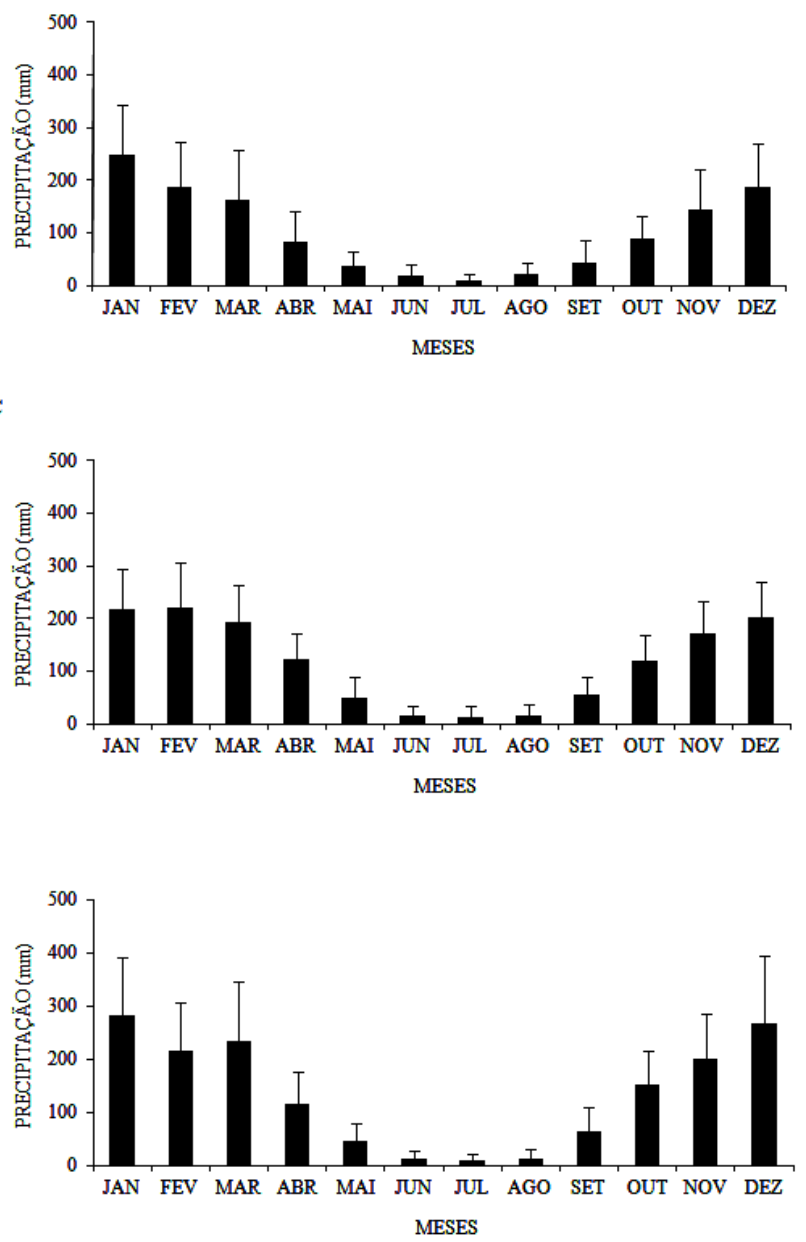

G

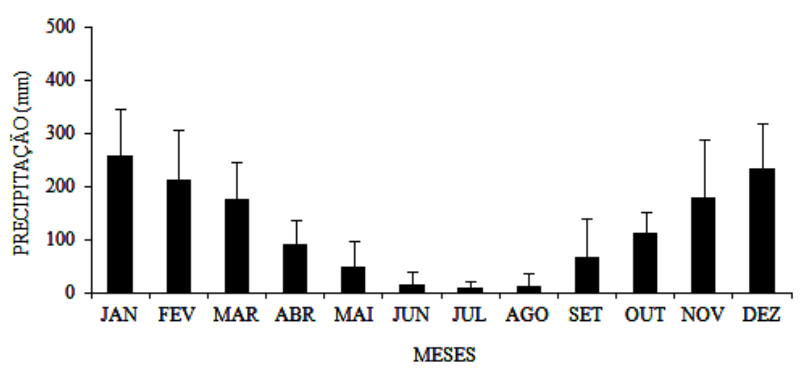

B
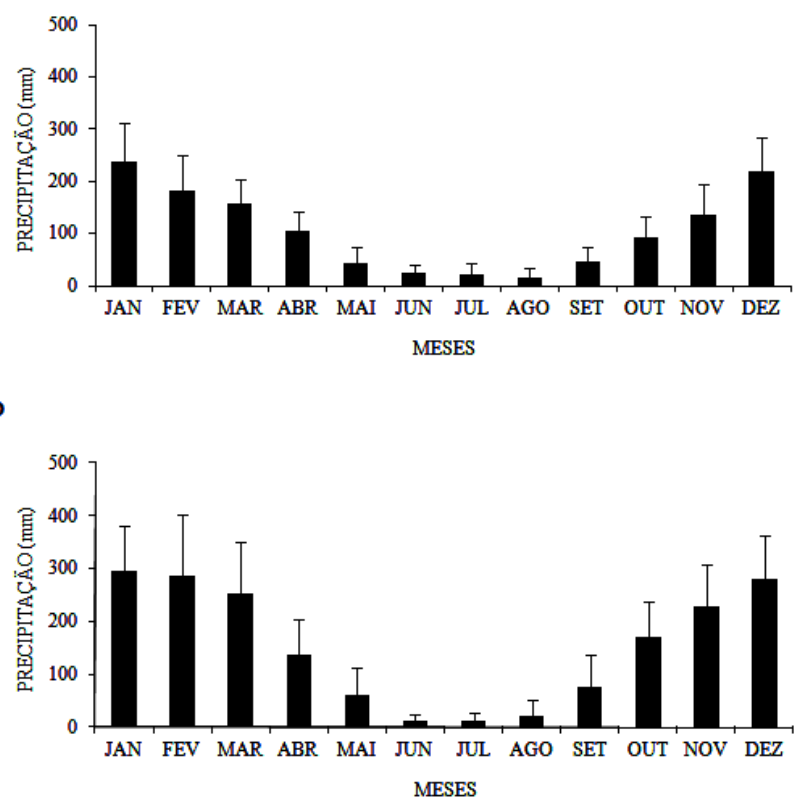

F

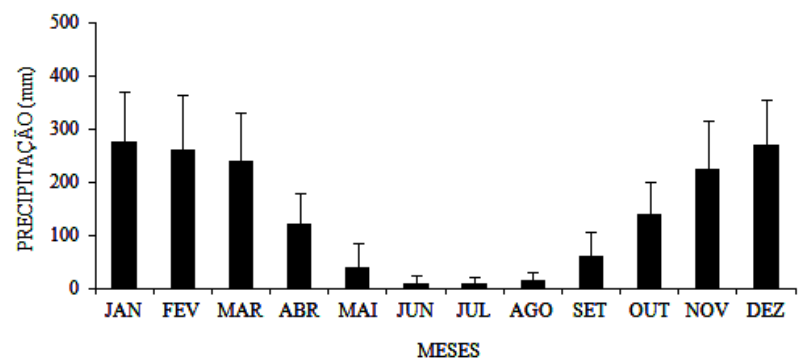

H

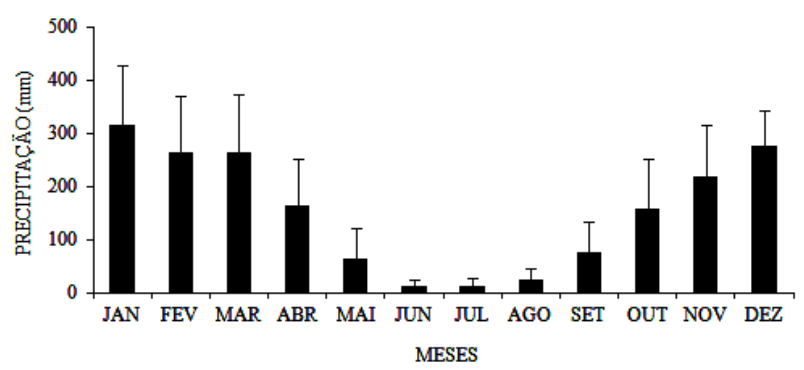

Figura 4 - Médias e desvios padrões mensais da precipitação nos municípios de: a. Barra do Bugres, b. Cáceres, c. Cuiabá, d. Diamantino, e. Jaciara, f. Nobres, g. Rondonópolis, h. Tangará da Serra.

Os municípios de Barra do Bugres (Figura 4a), Cáceres (Figura 4b) e Cuiabá (Figura 4c), todas localizadas nas regiões de menor elevação entre as áreas estudadas, apresentaram média em torno de $200 \mathrm{~mm}$ nos meses mais chuvosos, enquanto que nos municípios de Diamantino (Figura 4d), Nobres (Figura 4f) e Tangará da Serra (Figura 4h), as precipitações nos meses mais chuvosos se aproximaram dos $300 \mathrm{~mm}$.
A Tabela 2 apresenta a ocorrência mensal e anual de dias secos e chuvosos na região. Em média ocorrem 75,1 dias chuvosos e 289,9 dias secos ao ano, sendo que nos meses de Dezembro, Janeiro, Fevereiro e Março, são esperados mais de 10 dias chuvosos durante o mês. No mês de Novembro, observou-se a ocorrência de 8,9 dias chuvosos, já nos meses de Abril e Outubro estes valores ficam entre 5,5 e 6 dias. Para 
Tabela 2 - Ocorrência Mensal e anual de dias secos e chuvosos na região do arco das nascentes do Rio Paraguai

\begin{tabular}{|c|c|c|c|c|c|c|c|c|c|c|c|c|c|c|}
\hline Município & Condição & Jan & Fev & Mar & Abr & Mai & Jun & Jul & Ago & Set & Out & Nov & Dez & Anual \\
\hline Barra do & Chuvoso & 11,0 & 9,2 & 7,4 & 3,8 & 1,8 & 0,8 & 0,5 & 1,0 & 2,2 & 4,3 & 7,0 & 9,8 & 58,7 \\
\hline Bugres & Seco & 20,0 & 18,8 & 23,6 & 26,2 & 29,2 & 29,2 & 30,5 & 30,0 & 27,8 & 26,8 & 23,0 & 21,3 & 306,3 \\
\hline \multirow{2}{*}{ Cáceres } & Chuvoso & 16,4 & 13,6 & 9,8 & 4,9 & 1,1 & 0,6 & 0,5 & 0,4 & 1,5 & 4,1 & 8,1 & 16,7 & 77,6 \\
\hline & Seco & 14,6 & 14,4 & 21,2 & 25,1 & 29.9 & 29.4 & 30,5 & 30,6 & 28,5 & 26,9 & 21,9 & 14,3 & 287,4 \\
\hline \multirow{2}{*}{ Cuiabá } & Chuvoso & 12,4 & 11,3 & 10,2 & 5,7 & 1,8 & 0,5 & 0,4 & 0,6 & 2,5 & 5,4 & 8,0 & 11,1 & 70,0 \\
\hline & Seco & 18,6 & 16,7 & 20,8 & 24,3 & 29,2 & 29,5 & 30,6 & 30,4 & 27,5 & 25,6 & 22,0 & 19,9 & 295,0 \\
\hline \multirow{2}{*}{ Diamantino } & Chuvoso & 15,9 & 13,6 & 12,5 & 6,8 & 2,0 & 0,4 & 0,3 & 0,7 & 3,0 & 7,8 & 10,4 & 15,3 & 88,7 \\
\hline & Seco & 15,1 & 14,4 & 18,5 & 23,3 & 29,0 & 29,6 & 30,7 & 30,3 & 27,0 & 23,2 & 19,6 & 15,7 & 276,3 \\
\hline \multirow{2}{*}{ Jaciara } & Chuvoso & 14,0 & 12,3 & 13,4 & 6,1 & 1,8 & 0,4 & 0,4 & 0,6 & 2,9 & 7,3 & 10,8 & 14,4 & 84,4 \\
\hline & Seco & 17,0 & 15,7 & 17,6 & 23,9 & 29,2 & 29,6 & 30,6 & 30,4 & 27,1 & 23,7 & 19,2 & 16,6 & 280,6 \\
\hline \multirow{2}{*}{ Nobres } & Chuvoso & 13,1 & 11,1 & 10,1 & 5,8 & 1,7 & 0,4 & 0,3 & 0,7 & 2.7 & 5,9 & 9.4 & 11,8 & 73,1 \\
\hline & Seco & 17,9 & 16,9 & 20,9 & 24,2 & 29,3 & 29,6 & 30,7 & 30,3 & 27,3 & 25,1 & 20,6 & 19,2 & 291,9 \\
\hline \multirow{2}{*}{ Rondonópolis } & Chuvoso & 12,6 & 10,0 & 8,7 & 4,1 & 1,9 & 0,4 & 0,4 & 0,5 & 2,8 & 4,9 & 8,0 & 11,0 & 65,3 \\
\hline & Seco & 18,4 & 18,0 & 22,3 & 25,9 & 29,1 & 29,6 & 30,6 & 30,5 & 27,2 & 26,1 & 22,0 & 20,0 & 299,7 \\
\hline Tangará da & Chuvoso & 13,7 & 13,4 & 12,4 & 7,4 & 2,4 & 0,4 & 0,6 & 1,0 & 3,1 & 6,9 & 9,2 & 12,9 & 83,2 \\
\hline Serra & Seco & 17,3 & 14,6 & 18,6 & 22,6 & 28,6 & 29,6 & 30,4 & 30,0 & 26,9 & 24,1 & 20,8 & 18,1 & 281,8 \\
\hline \multirow{2}{*}{ Média } & Chuvoso & 13,6 & 11,8 & 10,6 & 5,6 & 1,8 & 0,5 & 0,4 & 0,7 & 2,6 & 5,8 & 8,9 & 12,9 & 75,1 \\
\hline & Seco & 17,4 & 16,2 & 20,4 & 24,4 & 29,2 & 29,5 & 30,6 & 30,3 & 27,4 & 25,2 & 21,1 & 18,1 & 289,9 \\
\hline
\end{tabular}

os demais meses valores esperados situam-se abaixo de 3 dias chuvosos.

Entre os municípios em estudo, Barra do Bugres e Diamantino apresentaram a menor e a maior média de ocorrência de dias chuvosos durante o ano, com um total de 58,7 e 88,7 dias respectivamente, sendo que no primeiro, apenas o mês de Janeiro ultrapassa a média de 10 dias chuvosos. Os meses de Dezembro e Janeiro em Cáceres, e o mês de Janeiro em Diamantino têm comportamento incomum entre a série de dados em estudo, onde o número de dias chuvosos supera o de dias secos (Tabela 2). Estes dados são de grande auxílio às atividades agrícolas, podendo auxiliar na tomada de decisões sobre atividades que são favorecidas por períodos de estiagem, bem como, aquelas que devem ser realizadas em períodos chuvosos (Fidelis et al., 2003).

Os valores dos parâmetros que permitem o cálculo da função Gama, estão expostos na Tabela 3. Pode-se observar que os valores do parâmetro de escala $(\beta)$ não excederam a 100 em nenhum dos meses para todos os municípios analisados, possibilitando assim a utilização da Distribuição Gama na estimativa das precipitações prováveis para a região. De acordo com Thom (1958), para valores de $\beta$ superiores a 100 a Distribuição Gama incompleta não deve ser utilizada.
Os índices prováveis de precipitação na região em estudo apresentadas na Figura 5, demonstram que em geral a precipitação média mensal se manteve abaixo do nível esperado à 50\% de probabilidade, isto ocorre pelo fato de que as precipitações com valores acima da média possuem maior desvios que as ocorridas abaixo desta. No Brasil é comum a utilização da média de precipitação nos estudos ligados ao dimensionamento de sistemas de irrigação, o que, em regiões onde existem grandes oscilações interanuais das chuvas (o que geralmente é comum, principalmente no cenário atual de mudanças climáticas), podem acarretar em subdimensionamento destes sistemas e consequente insucesso da atividade (Fietz et al., 1998).

Analisando a probabilidade de $75 \%$ dos cinco meses mais chuvosos na região, visualiza-se que a máxima e mínima precipitação esperada foi de: Novembro; 168,63 mm no município de Diamantino (Figura 5d) e 83,85 mm em Barra do Bugres (Figura 5a), Dezembro; 228,21 mm em Tangará da Serra (Figura 5h) e 123,94 mm em Barra do Bugres, Janeiro; 229,98 no município de Tangará de Serra e 160,17 mm em Cuiabá (Figura 4c), Fevereiro; 202,16 mm em Diamantino e 122,46 em Barra do Bugres e Março; 182,45 mm em Tangará da Serra e 89,01 mm em Barra do Bugres. 
A $\rightarrow-10 \% \rightarrow-25 \% \rightarrow-50 \% \rightarrow 75 \% \rightarrow-90 \%$

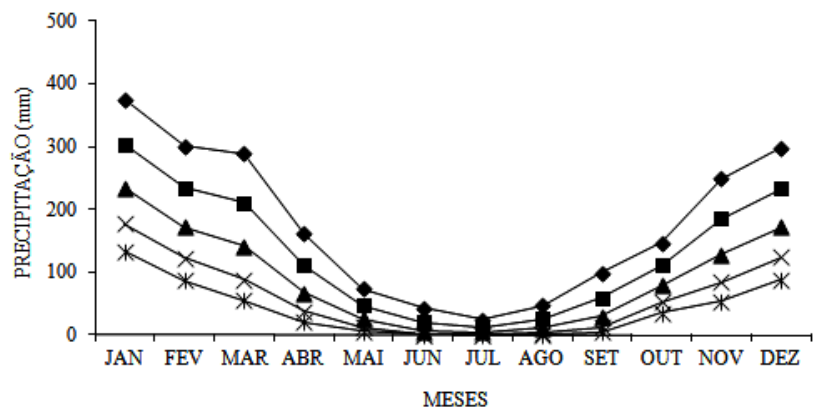

C $\rightarrow-10 \% \rightarrow-25 \% \rightarrow-50 \% \rightarrow-75 \% \rightarrow-90 \%$

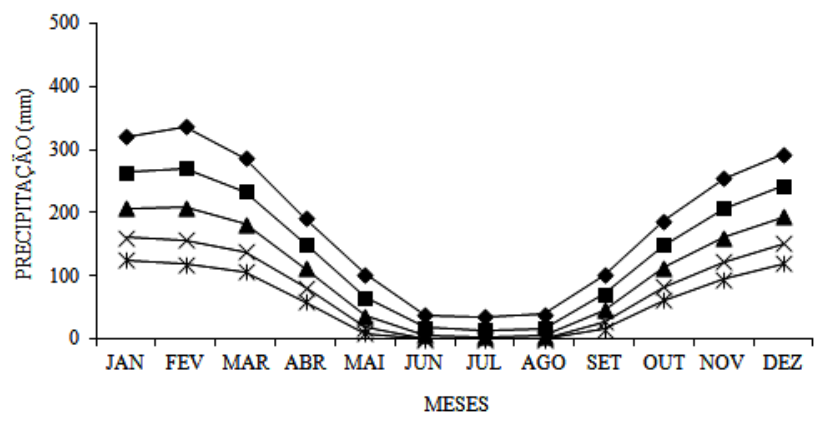

E $\rightarrow-10 \% \rightarrow-25 \% \rightarrow 50 \% \rightarrow-75 \% \rightarrow-90 \%$

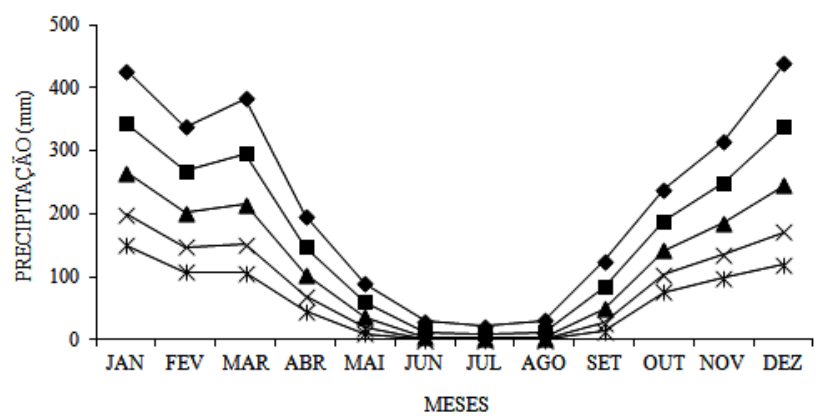

G $\rightarrow-10 \% \rightarrow-25 \% \rightarrow-50 \% \rightarrow-75 \% \rightarrow-90 \%$

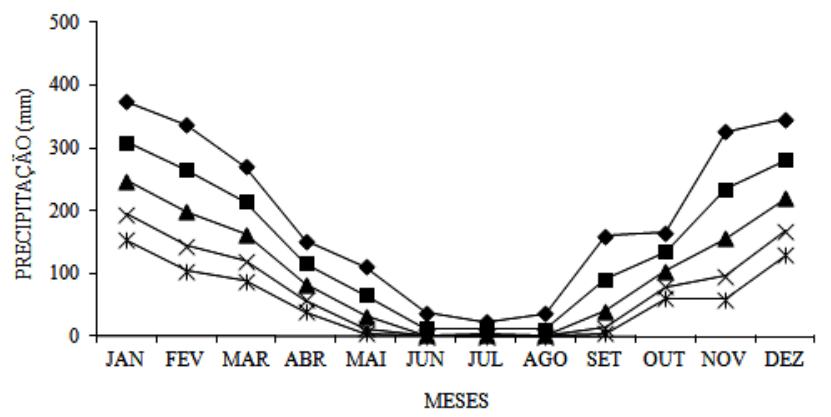

B

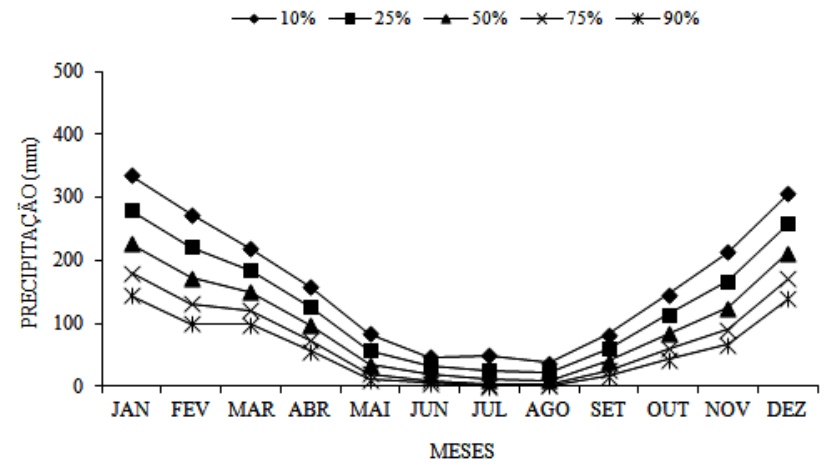

D

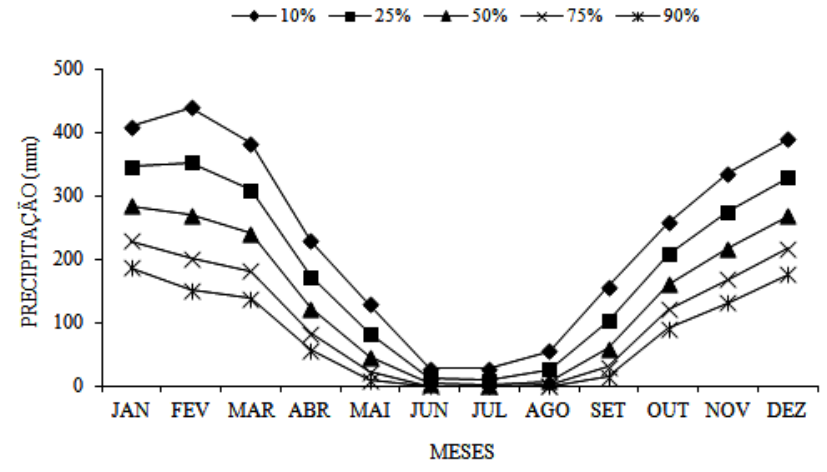

$\mathbf{F}$

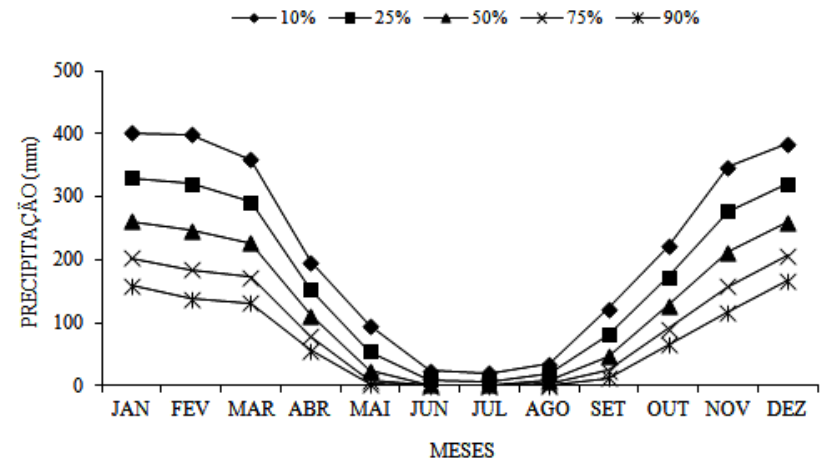

H

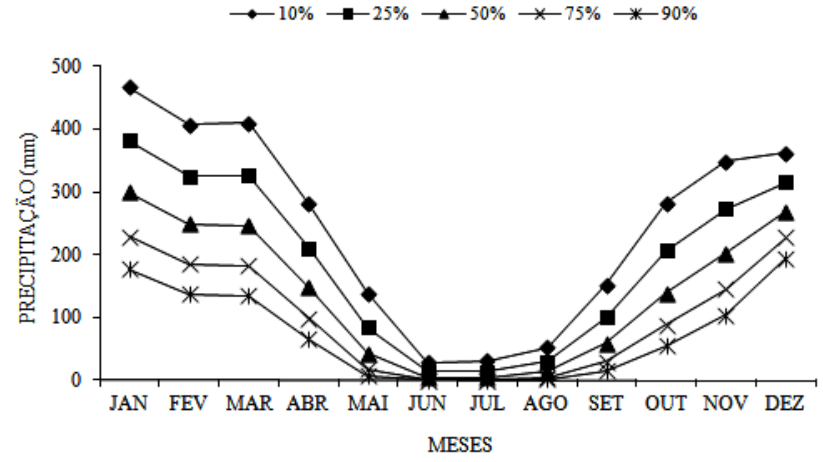

Figura 5. Diferentes níveis probabilísticos de precipitação determinados pela função Gama nos municípios de: a. Barra do Bugres, b. Cáceres, c. Cuiabá, d. Diamantino, e. Jaciara, f. Nobres, g. Rondonópolis, h. Tangará da Serra. 
Tabela 3 - Valores dos parâmetros de forma $(\alpha)$ e escala $(\beta)$ para períodos mensais.

\begin{tabular}{|c|c|c|c|c|c|c|c|c|c|c|c|c|c|c|}
\hline Município & Parâmetro & Jan & Fev & Mar & Abr & Mai & Jun & Jul & Ago & Set & Out & Nov & Dez & Anual \\
\hline Barra do & $\alpha$ & 6,56 & 4,62 & 2,75 & 1,84 & 1,30 & 0,44 & 0,50 & 0,69 & 0,98 & 3,61 & 3,19 & 4,84 & 17,59 \\
\hline Bugres & $\beta$ & 37,67 & 40,16 & 58,26 & 44,31 & 26,31 & 35,14 & 18,18 & 27,51 & 43,76 & 23,91 & 44,61 & 38,28 & 68,70 \\
\hline \multirow{2}{*}{ Cáceres } & $\alpha$ & 9,58 & 6,90 & 10,58 & 6,34 & 1,91 & 1,61 & 0,62 & 0,71 & 2,69 & 4,60 & 5,11 & 10,98 & 45,07 \\
\hline & $\beta$ & 24,48 & 26,19 & 14,67 & 16,21 & 22,10 & 14,23 & 30,62 & 21,00 & 16,93 & 19,54 & 26,17 & 19,89 & 27,96 \\
\hline \multirow{2}{*}{ Cuiabá } & $\alpha$ & 7,69 & 6,37 & 7,04 & 5,11 & 1,37 & 0,45 & 0,34 & 0,38 & 2,20 & 5,70 & 7,02 & 8,51 & 47,08 \\
\hline & $\beta$ & 28,18 & 34,51 & 27,08 & 23,52 & 35,16 & 30,18 & 34,85 & 35,73 & 24,17 & 20,99 & 24,09 & 23,64 & 29,26 \\
\hline \multirow{2}{*}{ Diamantino } & $\alpha$ & 11,11 & 6,16 & 6,76 & 3,69 & 1,33 & 0,44 & 0,24 & 0,46 & 1,51 & 6,43 & 7,81 & 10,78 & 44,09 \\
\hline & $\beta$ & 26,37 & 46,37 & 37,43 & 36,56 & 45,13 & 23,40 & 39,34 & 44,03 & 50,10 & 26,35 & 29,12 & 25,77 & 41,21 \\
\hline \multirow{2}{*}{ Jaciara } & $\alpha$ & 6,41 & 5,41 & 4,33 & 3,44 & 1,65 & 0,38 & 0,37 & 0,29 & 1,64 & 5,41 & 5,19 & 4,22 & 28,01 \\
\hline & $\beta$ & 43,55 & 39,68 & 53,80 & 32,98 & 26,47 & 26,53 & 20,26 & 35,95 & 37,21 & 27,95 & 38,27 & 62,92 & 56,69 \\
\hline \multirow{2}{*}{ Nobres } & $\alpha$ & 7,98 & 6,23 & 6,86 & 4,46 & 0,77 & 0,30 & 0,24 & 0,67 & 1,54 & 4,73 & 5,94 & 9,78 & 57,35 \\
\hline & $\beta$ & 34,19 & 41,71 & 34,73 & 27,00 & 50,90 & 27,29 & 28,32 & 20,30 & 38,16 & 28,90 & 37,71 & 27,53 & 28,73 \\
\hline \multirow{2}{*}{ Rondonópolis } & $\alpha$ & 8,68 & 5,13 & 5,69 & 3,91 & 0,93 & 0,24 & 0,44 & 0,21 & 0,79 & 6,86 & 2,61 & 7,17 & 14,69 \\
\hline & $\beta$ & 29,64 & 41,37 & 30,43 & 23,23 & 50,66 & 52,24 & 19,25 & 55,50 & 83,43 & 16,03 & 68,37 & 32,20 & 94,06 \\
\hline Tangará da & $\alpha$ & 7,39 & 5,99 & 5,70 & 3,44 & 1,03 & 0,49 & 0,43 & 0,84 & 1,56 & 2,83 & 4,88 & 17,39 & 34,27 \\
\hline Serra & $\beta$ & 42,43 & 43,96 & 46,08 & 47,53 & 59,36 & 21,23 & 26,17 & 26,20 & 47,37 & 55,54 & 44,57 & 15,82 & 53,43 \\
\hline
\end{tabular}

Uma comparação paralela entre os dados das Figuras 3 e 4 demonstra que em meses onde o desvio padrão é menor existem menores discrepâncias entre os índices de precipitação esperados a 10 e $90 \%$, indicando uma menor variação interanual da precipitação, uma vez que para o cálculo da função Gama tem-se como base a média e o desvio padrão de determinada amostra. Este é o caso da estação de Cáceres como um todo (Figura 4b), Rondonópolis no mês de Outubro (Figura 4g) e Tangará da Serra no mês de Dezembro (Figura 4h).

A análise dos resultados mostra que em geral os padrões das chuvas na região apresentam grande homogeneidade, sendo que os níveis esperados no período chuvoso dificilmente variam muito entre os anos, bem como, nos períodos secos, em raros anos, ocorrem precipitações significativas, o que permite um melhor planejamento e garantia de resultados positivos, tanto para culturas irrigadas, quanto para as de sequeiro.

\section{CONCLUSÕES}

1. Todas as estações em estudo demonstraram comportamento semelhante com relação à distribuição sazonal das chuvas, podendo ser observados quatro períodos distintos sendo designados como chuvoso, transição entre o período chuvoso e seco (transição 1), seco e transição entre o período seco e chuvoso (transição 2).

2. Podem ser observadas grandes variações espaciais nas médias anuais de precipitação, fato que esteve significativamente correlacionado a altitude de cada estação.

3. Os meses onde são registrados os maiores valores de precipitação em toda a região correspondem ao período de Novembro a Março.

4. As lâminas médias de precipitação para períodos mensais são inferiores as esperadas em 50\% de probabilidade, portanto, muito abaixo dos índices recomendados, que correspondem a $75 \%$.

\section{AGRADECIMENTOS}

À Fundação de Amparo a Pesquisa do Estado do Mato Grosso (FAPEMAT), pelo auxilio financeiro na realização do projeto de pesquisa e pela concessão de bolsas de Iniciação Científica.

\section{REFERÊNCIAS BIBLIOGRÁFICAS}

ASSAD, E. D.; MACEDO, M. A.; CÂMARA, G.; OLIVEIRA, J. C.; BARBOSA, A. M. Avaliação de métodos para espacialização de índices de necessidade hídrica das culturas e sua aplicação em zoneamento agrícola. Revista Brasileira de Agrometeorologia, Passo Fundo, 9(3), 581-587, 2001. ASSIS, F. N.; ARRUDA, H. V.; PEREIRA, A. R. Aplicações de estatística à climatologia. 1 ed. Pelotas: UFPel, 1996. 161p. 
CARVAlHO, J. R. P; ASSAD, E. D. Análise espacial da precipitação pluviométrica no Estado de São Paulo: comparação de métodos de interpolação. Engenharia Agrícola, Jaboticabal, 25(1), 377-384, 2005.

COLLISCHONN, W.; TUCCI, C. E. M.; CLARKE, R. T. Variabilidade temporal no regime hidrológico da bacia do rio Paraguai. Revista Brasileira de Recursos Hídricos, Porto Alegre, 8(1), 201-211, 2003.

CUNHA, C. N.; JUNK, W. J. Year-to-year changes in water level drive the invasion of Vochysia divergence in Pantanal glassland. Applied Vegetation Science, Grangärde, 7, 103-110, 2004.

DIAS F. L. F.; MAZZA, J. A., MATSUOKA S.; PERECIN D.; MAULE R. F. Produtividade da cana-de-açúcar em relação a clima e solos da região noroeste do estado de São Paulo. Revista Brasileira de Ciência do Solo, Viçosa, 23(3), 627-634, 1999.

FARIA, R. T.; CARAMORI, P. H.; CHIBANA, E. Y.; BRITO, L. R. S. CLIMA - Programa computacional para organização e análise de dados meteorológicos. Engenharia Agrícola, Jaboticabal, 23(2), 372-387, 2003.

FIETZ, C. R.; FRIZZONE J. A.; FOLEGATTI, M. V.; URCHEI, M. A. Precipitação esperada, em diferentes níveis de probabilidade, na região de Dourados, MS. Ciência Rural, Santa Maria, 28(1), 29-34, 1998.

FIDELIS, R. R.; ROCHA, R. N. C.; LEITE, U. T.; TANCREDI, F. D. Alguns aspectos do plantio direto para a cultura da soja. Bioscience Journal, Uberlândia, 19(1), 23-31, 2003.

FIGUERÊDO, S. F.; POZZEBON, E. J.; FRIZZONE, J. A.; AZEVEDO, J. A.; GUERRA, A. F.; SILVA, E. M. Gerenciamento da Irrigação do Feijoeiro Baseado em Critérios Técnicos e Econômicos no Cerrado. Irriga, Botucatu, 13, 378-391, 2008.

FONTANA, D. C. Alterações micrometeorológicas na cultura da soja submetida a diferentes regimes hídricos. Pesquisa Agropecuária Brasileira, Brasília, 27(5), 661-669, 1992.

KELLER FILHO, T.; ASSAD, E. D.; LIMA, P. R. S. R. Regiões pluviometricamente homogêneas no Brasil. Pesquisa Agropecuária Brasileira, Brasília, 40(4), 311-322, 2005.
LIMA, J. S. S.; SILVA, S. A.; OLIVEIRA, R. B.; CECILIO, R. A.; XAVIER, A. C. Variabilidade temporal da precipitação mensal em Alegre - ES. Revista Ciência Agronômica, Fortaleza, 39(2), 327-332, 2008.

MELLO, C. R.; FERREIRA, D. F.; SILVA, A. M.; LIMA, J. $\mathrm{M}$. Análise de modelos matemáticos aplicados ao estudo de chuvas intensas. Revista Brasileira de Ciência do Solo, Viçosa, 25(3), 693-698, 2001.

MINUZZI, R. B.; SEDIYAMA, G. C.; BARBOSA, E. M.; MELO JÚNIOR, J. C. F.; CATALUNHA, M. J. Estudo climático do comportamento do período chuvoso no estado de Minas Gerais. Revista Ceres, Viçosa, 53, 266-275, 2006.

MURTA, R. M.; TEODORO, S. M.; BONOMO, P.; CHAVES, M.A. Precipitação pluvial mensal em níveis de probabilidade pela distribuição gama para duas localidades do sudoeste da Bahia. Revista Ciência e Agrotecnologia, Lavras, 29(5), 988-994, 2005.

NIMER, E. Climatologia do Brasil. 2 ed. Rio de Janeiro: IBGE, 1989. 421p.

RANIERI, S. B. L.; SPAROVEK, G.; SOUZA, M. P.; DOURADO NETO, D. Aplicação de índice comparativo na avaliação do risco de degradação das terras. Revista Brasileira de Ciência do Solo, Viçosa, 22(4), 751-760, 1998.

SANS, L. M. A.; SANTANA, D. P. Cultivo do Milho: Clima e solo. http://www.cnpms.embrapa.br/publicacoes/milho/ clima.htm.18 Set. 2009.

SILVA, J. C.; HELDWEIN, A. B. MARTINS, F. B.; TRENTIN, G.; GRIMM, E. L. Análise de distribuição de chuva para Santa Maria, RS. Revista Brasileira de Engenharia Agrícola e Ambiental, Campina Grande, 11(1), 67-72, 2007.

SMITH, M. The application of climatic data for planning and management of sustainable rainfed and irrigated crop production. Agricultural and Forest Meteorology, Amsterdam, 103, 99-108, 2000.

THOM, H. C. S. A note on the gama distribution. Monthly Weather Review, Washington, 86, 117-122, 1958. 